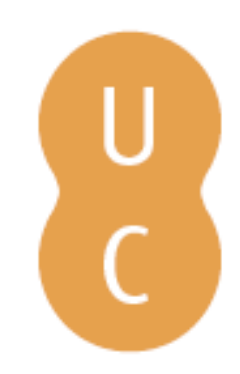

\title{
pombalina
}

\section{Pensar la educación desde la experiencia}

Autor(es): $\quad \begin{array}{ll}\text { Bárcena Orbe, Fernando; Larrosa Bondía, Jorge; Mélich Sangrá, Joan- } \\ \text { Carles }\end{array}$

Publicado por: Imprensa da Universidade de Coimbra

URL

persistente: URI:http://hdl.handle.net/10316.2/38392

DOI: $\quad$ DOI:http://dx.doi.org/10.14195/978-989-26-0486-2_14

Accessed : $\quad$ 26-Apr-2023 16:14:52

A navegação consulta e descarregamento dos títulos inseridos nas Bibliotecas Digitais UC Digitalis, UC Pombalina e UC Impactum, pressupõem a aceitação plena e sem reservas dos Termos e Condições de Uso destas Bibliotecas Digitais, disponíveis em https://digitalis.uc.pt/pt-pt/termos.

Conforme exposto nos referidos Termos e Condições de Uso, o descarregamento de títulos de acesso restrito requer uma licença válida de autorização devendo o utilizador aceder ao(s) documento(s) a partir de um endereço de IP da instituição detentora da supramencionada licença.

Ao utilizador é apenas permitido o descarregamento para uso pessoal, pelo que o emprego do(s) título(s) descarregado(s) para outro fim, designadamente comercial, carece de autorização do respetivo autor ou editor da obra.

Na medida em que todas as obras da UC Digitalis se encontram protegidas pelo Código do Direito de Autor e Direitos Conexos e demais legislação aplicável, toda a cópia, parcial ou total, deste documento, nos casos em que é legalmente admitida, deverá conter ou fazer-se acompanhar por este aviso.

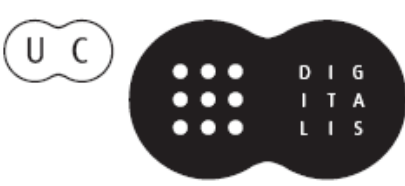


João Boavida

Ángel García del Dujo

Coordenação

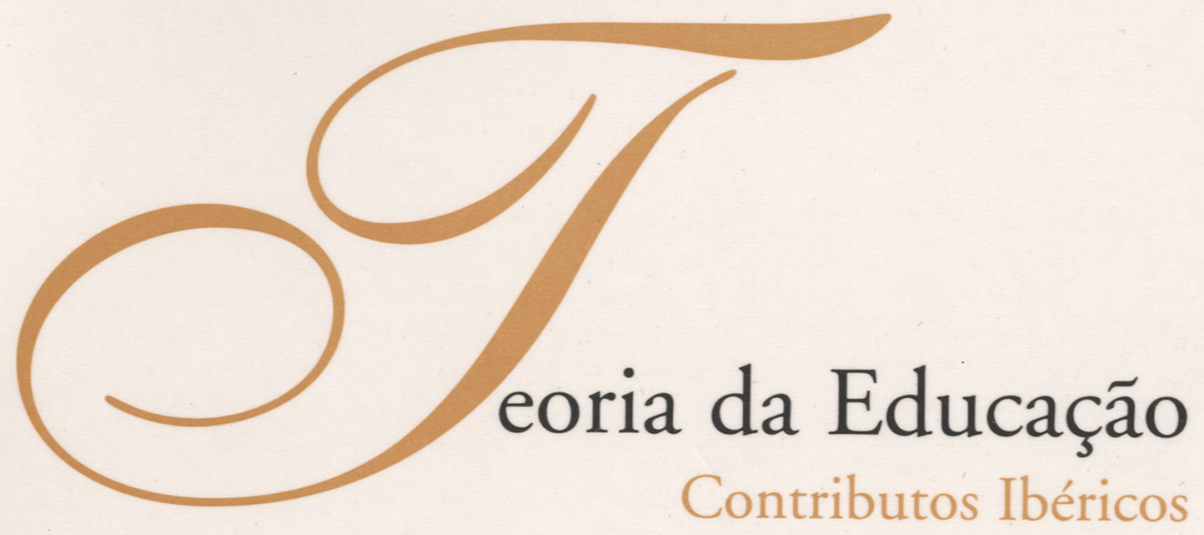


Fernando Bárcena Orbe

Universidad Complutense de Madrid

Jorge Larrosa Bondía

Universidad de Barcelona

Joan-Carles Mélich Sangrá

Universidad Autónoma de Barcelona

Pensar 1a Educación desde 1 a experiencia

La experiencia es el lugar donde tocamos los límites de nuestro lenguaje.

Giorgio Agaraben, Infancia e historia

En su constitución teórica típicamente moderna el saber pedagógico que trata de fundar las prácticas educativas tiene clara su apuesta - la claridad cognitiva, que es expresión de un orden emanado de una razón legislativa y ha consumado sus propias renuncias: eliminar la incertidumbre usurpando a la experiencia de la educación su carácter hermenêutico. Allí donde se presenta un «contexto hermenêutico» surgen problemas de significación y sentido. La incertidumbre provoca irritación, pues en lo ambivalente el sujeto tiene que leer las situaciones interpretándolas, tiene que elegir y decidirse. Y hay que elegir, pues allí donde no hay posibilidad de elegir todo es posible y, si «todo es posible», se sientan las bases para una práctica de corte totalitario.

Desde una tradición de pensamiento que proviene de Platón y pasa por Descartes, Locke y Kant, el horror a la incertidumbre significó varias cosas, según el ámbito donde se aplicase. En política, significó la expulsión de los extraños y la legalización de lo sancionado como excepción, donde lo 
excepcional deviene regla de lo cotidiano (Agamben, 2004, 11). En el ámbito intelectual significó la deslegitimación de los fundamentos del conocimiento filosóficamente incontrolables (los que provienen de la experiencia). En todo este proceso es el experto quien sabe y quien decide. Pero esta tradición de la filosofía fundacional tiene su efecto implacable en el orden del pensamiento, pues un pensamiento correcto es el que busca lo que hay tras las meras apariencias. Y esto no significa otra cosa que declarar una guerra legal $-\mathrm{y}$ racionalmente legitimada $-\mathrm{a}$ lo que no es sino mera apariencia. El resultado de todo ello es el monumental olvido de que también entendemos las cosas experimentándolas de forma corpórea, relacional: en situación. Comprendemos a partir de nuestros cuerpos, a través de las relaciones que establecemos con los demás y de las formas a través de las cuales nos ponemos en contacto con los objetos del mundo. Usamos el lenguaje como medio para comunicarnos, pero también aspiramos a hacer del lenguaje el fin de todo aquello que consideremos comunicación humana. $\mathrm{Y}$, por eso, tan importante como lo que decimos es lo que mostramos y callamos. Lo que importa es la experiencia.

Un discurso de la experiencia en educación es hoy, sin embargo, empresa difícil. La práctica de la educación, tal y como es pensada por algunos de sus defensores en Teoría de la Educación, sirve para reforzar una mentalidad clasificatoria:

La práctica típicamente moderna, la sustancia de la políica moderna, del intelecto moderno, de la vida moderna, es el esfuerzo por exterminar la ambivalencia: un esfuerzo por definir precisamente (Bauman, 2005, 27).

Una mentalidad cuyas palabras fetiche enuncian el diseño, la manipulación, la ingeniería, la regla, la clasificación, el orden y la jerarquía. Una mentalidad cuyo proyecto es la larga historia de múltiples diseños de lo real, los cuales buscan imponer nuevos y sucesivos «nuevos órdenes» de los que, evidentemente, siempre serán expulsados muchos de los que no encajan dentro del sistema previsto. Desde esta mentalidad, la única crítica legítima, pedagógicamente hablando, sería la que termina objetivándose en un «proyecto». 
Lo que pretendemos en este texto es tratar de situar distintas dimensiones de lo pedagógico, y del pensamiento sobre 0 para la educación, en lugares distintos a los dominantes. En lugares muy cercanos al cuerpo —entendido como lugar de la experiencia - como escenario de lucha y de resistencia, y también como finitud, como nacimiento, como muerte, como atención 0 placer, como expresión y como fatiga. Pero se trata, también, de apuntar a un pensamiento no metafísico de la educación que enfrente la singularidad, la contingencia, la falta de sentido, la ambivalencia y la incertidumbre. Y todo ello para marcar diferencias con respecto a los lenguajes impersonales de la racionalidad tecno-científica que se han instalado en lo pedagógico. De marcar diferencias con respecto a las definiciones intencionales de la educación, respecto a la idea de la educación como algo que tiene que ver con ese vocabulario ideado para neutralizar la ambivalencia —el lenguaje de los objetivos, las planificaciones y las estrategias, el de los proyectos, los programas y las acciones controladas - marcar diferencias, en fin, con respecto a esa manera de entender la educación que tiene su criterio fundamental en la eficacia y cuya figura emblemática es la del experto.

Hemos dividido este texto en tres partes. La primera, que escribió Fernando Bárcena, plantea las dificultades de un regreso a la experiencia en educación bajo el signo de los discursos pedagógicos dominantes en Teoría de la Educación. Para ello, tratamos de poner en relación la educación con una triple experiencia original de lo pedagógico — la del viaje, la de la salida al exterior y la del comienzo —en un intento de pensar la educación como acontecimiento. La segunda parte, que escribió Jorge Larrosa, intenta poner en contraste una manera impersonal de pensar y decir la educación con un lenguaje que sería algo así como una forma de pensar y expresar la educación que no pretende adoptar el punto de vista de ningún lugar, sino que es consciente de que se habla y se piensa siempre desde una condición subjetiva y personal. Aquí, la experiencia exige un lenguaje atravesado de pasión que enuncia la singularidad de lo singular; un lenguaje para la conversación más que para el debate, la discusión o el 
diálogo, entendidas como formas de comunicación obligatorias. La tercera parte, que escribió Joan-Carles Mélich, presenta las líneas generales de una pedagogía de la finitud, y especialmente trata de poner de manifiesto la ineludible situacionalidad y relacionalidad de los seres humanos en sus mundos. A partir de aquí, se plantea la dimensión ética de la acción educativa. Se trata, en suma, de apuntar a un pensamiento de la educación desde un lenguaje de la experiencia que es profundamente ético, aunque no se derive de una ética del deber ni de una ética ligada a la legislación obligatoria de la razón.

El lector va a notar enseguida que el texto está escrito —en realidad hablado —en primera persona. Cada uno de nosotros ha tratado de escribir como quien habla a alguien que conoce y está mirando cara a cara, hablando con una cierta intimidad y desde una cierta cercanía que no anula las diferencias intelectuales ni la importancia de los argumentos desplegados. 11

\section{La educación y el regreso de la experiencia}

Un problema del discurso dominante sobre la educación es que se presenta a sí mismo como un discurso ya blindado contra cualquier tipo de crítica. Este discurso se sirve ahora de las nuevas tecnologías de la información y de la expresión «sociedad del conocimiento»—que ha llegado a convertirse en una fórmula mágica que reúne todos los retos pedagógicos que han de asumirse - para imponer un nuevo totalitarismo epistemológico y metodológico. En su blindaje, este discurso ya ordenado impone una política del silencio que hace de cualquier posible crítica la manifestación más clara y evidente de lo reaccionario. Sorprende que, si tradicionalmente el intelectual era justamente quien manifestaba su progresismo en su oposición argumentada al sistema, ahora sea lo contrario. La cuestión que planteo es muy parecida al argumento que el esloveno Slavoj Éizek desarrolla en su libro ¿Quién dijo 
totalitarismo? Hay expresiones, como la misma de totalitarismo, cuyo uso sobreabundante, y banalizado, acaba convirtiéndose en un subterfugio que, en vez de permitir pensar, obligándonos a adquirir una nueva visión de la realidad histórica que describe, nos descarga del deber de pensar e incluso impide todo pensamiento crítico e independiente (Zizek, 2002, 13).

Hay una aspiración moralizante en ese discurso. Y, en realidad, es 10 mismo que se revista de un formato tecnológico 0 con un discurso más crítico-reflexivo, como veremos más tarde con mayor detalle. Su núcleo conceptual se resume en la idea de que la calidad de la educación —otro fetiche pedagógico — depende de la calidad de las motivaciones de los sujetos a favor, en un caso del uso de los recursos de la sociedad de la información, y en el otro de un esquema de prácticas reflexivas que, por más que reivindiquen el carácter singular de los acontecimientos educativos, anhela instituirse en un discurso dotado de eficacia, rigor y legitimidad científica. Es a este nivel de una motivación favorable donde se juega eso que llamamos calidad de la educación. La antigua relación pedagógica mediada por la palabra y los gestos es sustituida ahora por una comunidad virtual - los enfoques crítico-reflexivos también han sabido hacer un buen uso de la sociedad del conocimiento — que acaba por anular lo que en otro tiempo llamábamos comunidad de sentido. La experiencia de un maestro en un aula intentando hacer «ver» a sus alumnos todo un mundo de posibilidades mediante el solo recurso de la magia de la palabra es, cada vez más, algo inusual ante la invasión de uno de los dioses de la ciudad moderna; ahora ya no hace falta la semipenumbra de una sala de cine para proyectar las imágenes, pues la era digital nos proporciona un arma más eficaz, el PowerPoint.

Para lograr ese bien común de la codiciada calidad de la educación —una expresión previamente definida por la mentalidad clasificatoria y de diseño moderna - todos los miembros de la sociedad educativa han de actuar pensando de modo idéntico y único: han de ser unos buenos ciudadanos de la comunidad cognitiva a la que pertenecen (no se insistirá bastante en 
que cognición y pensamiento no son la misma cosa, pero esta diferencia también la hemos olvidado). De modo que oponerse a este modelo es oponerse a la misma idea de la calidad pretendida. Así que la construcción de un nuevo orden es posible sólo si va asociado a la construcción de una nueva noción de educación, de un nuevo tipo de educando (o de alumno) y de un nuevo tipo de educador (o profesor), porque no puede haber un buen orden sin actores saneados. De aquí es fácil asignar a la educación diversas funciones, desde la promoción de la regeneración moral — entendida como modificación de las motivaciones de los individuos - hasta su socialización en el nuevo ethos a las generaciones venideras (normalización de conductas). Se entiende que el principal problema de este modelo consiste en que anula la posibilidad de control del sujeto, al crear las condiciones para que cualquier resistencia al programa terapéutico sea interpretada como una expresión efectiva de la imperfección que debe superarse para lograr el nuevo orden deseado. Así, la resistencia al nuevo orden no sería más que una expresión del «hombre viejo» que hay que reformar 0 , en su caso, dejar de lado.

Sin embargo, invito al lector a que considere otra historia. A que piense, por ejemplo, que la memoria original de lo pedagógico remite a un tipo de experiencia que es un viaje en el fondo impensable desde el régimen de la racionalidad tecno-científica: el esclavo pedagogo que conduce al niño hasta la escuela. En esta experiencia original se dan cita tres elementos: el viaje, la salida hacia el exterior y la experiencia del comienzo (Serres, 1993, 23). Esta triple experiencia — viaje, salida y comienzo —está contenida en una de las derivas latinas de la palabra educación; educere, es dirigir o salir hacia fuera, conducir a alguien fuera de lo propio, más allá del lugar conocido y habitado, empujarlo hacia lo extraño. Aquí, lector, puedes encontrar una historia de la pedagogía bien interesante: Erfahrung es Fahrt, la experiencia es un viaje y, por eso, pensada como experiencia, la educación es una salida hacia un afuera donde no todo puede planificarse ni programarse. Se trata de un viaje en el que se hace una experiencia, la de una confrontación 
con lo extraño, la que consiste, también, en escapar de las identidades fijas e inmutables, desligarse, en fin, de los lazos que «fueron impuestos en el terror obediente, familiar, social, impersonal y mudo de los primeros años» (Quignard, 1998, 218). El viaje, pues, como experiencia, como salida que nos confronta con lo extraño y como posibilidad de un nuevo comienzo.

Llevado a su límite, ese hacer experiencia es una praxis cuyo sentido reside en su misma realización. Aquí, actuar es iniciar algo nuevo, tomar una iniciativa que se despliega más allá del tiempo de quien inicia el primer gesto. Quien inicia la acción, o quien pronuncia la primera palabra, no cierra el discurso, sino que lo abre. Ese nuevo comienzo permite que la educación sea una experiencia relacionada, no ya con los significados pedagógicos dados, sino con la creación del sentido. El problema reside en que, como inicio y como comienzo, el tiempo de la educación, que no es cronometrable ni programable, tampoco es del todo pensable: «El comienzo del tiempo es algo que no podemos pensar [...]: ninguna conciencia puede vivirse a sí misma en trance de dar comienz0» (Blumenberg, 2004, 15). Estoy planteando aquí un pensamiento del comienzo, para poder a su vez pensar una educación desde la experiencia que precede a todo intento de [Rescribirla. Pensar la educación al margen de un punto de vista tanto «tecnológico» como «metafísico», porque la tecnología (que es un sistema) hace de la experiencia experimento y porque la metafísica es aquel saber que se sitúa más allá de toda experiencia sensible. En ambos casos, la «búsqueda del origen» encubre la pretensión de recoger la esencia exacta de la cosa, 0 sea, una identidad meticulosamente replegada sobre sí misma, una presencia siempre idéntica e inmutable. Un pensamiento del comienzo busca otra cosa: «Localizar la singularidad de los acontecimientos, fuera de toda finalidad monótona» (Foucault, 2000, 12).

Podría decirse, entonces, que cualquier intento por pensar la educación no sería más que la elaboración de un discurso — un saber, unas prácticas, el diseño de unas acciones, la explicitación de unas reglas — cuyo objeto es esa experiencia primordial del viaje, de la salida y del comienzo en un 
espacio y un tiempo dados. Pero no es la misma cosa esa experiencia, en su específica originalidad y singularidad, que su explicitación en un discurso que se pretende racional y en el contexto de un particular discurso pedagógico. Así como no hay filosofía sin escritura (y sin textos que argumenten), tampoco hay teoría de la educación sin escritura pedagógica (y sin argumentos sobre la educación). Bajo este punto de vista, una teoría de la educación, en su pretensión de explicar las reglas que funda la experiencia misma de eso que llamamos educación, no es otra cosa que una práctica distinta de la experiencia de la educación misma, o lo que es lo mismo, se trata de la transformación de una experiencia original en otra práctica que pretende explicarla, describirla, decirla. Como toda elaboración teórica de cierta complejidad, esa teoría de la educación se asigna la tarea de conformar la figura conceptual de la experiencia que tiene como objeto de estudio; y, como decía Wittgenstein, la filosofía, al registrar un juego precedente, en realidad lo transforma. A la pedagogía, como discurso que pretende conformar la figura conceptual de la educación, le ocurre lo mismo que sucedió con el paso de la oralidad a la escritura: una lengua no es la misma cuando se escribe que antes de hacerlo, como las palabras de Sócrates no son las mismas en su oralidad que en la escritura de los diálogos de Platón, porque la «escritura cambia aquello que refleja y siempre traiciona lo que delata» (Pardo, 2004, 59). Cada vez que tratamos de volver explícitas las reglas de juego que implícitamente practican otros, cuando creemos que estamos «diciendo» la verdad sobre sus prácticas, lo que en realidad hacemos es mudarla en otro juego con pretensiones de una verdad previamente fijada en sus contornos. Al escribir sobre educación, elaborando saberes racionales, componemos una serie de reglas que intentan volver explícito lo implícito, visible lo oculto, para hacer hablar el silencio de lo real, que como tal sólo es lo que es. Pero, ipodemos todavía pensar la «verdad» de la educación desde esa experiencia primordial? La cuestión determinante es: ¿se aprende a comenzar?, jes posible un aprendizaje del comienzo si, como acaecimiento, el comienzo tiene la forma de un presente intempestivo, la figura misma 
de lo sorprendente y del instante? Desde la mentalidad moderna diríamos: un mundo ordenado es aquel que sabe con seguridad (sin ambivalencia ni incertidumbre) cómo continuar. Desde el lenguaje de la experiencia decimos: incipere no discitur, «no se aprenden los comienzos». ¿No se aprenden o no se enseñan?, ¿se dicen 0 simplemente se muestran?

Para responder a estas cuestiones, me resulta esencial volver a la imagen de alguien que intenta «decir» (y explicar) las reglas que el otro tan sólo podría «mostrar» (usándolas desde su saber experiencial). La diferencia entre uno y otro es la misma que hay entre un «profesor» y un «maestro». El maestro, más que explicar 0 dar una clase teórica, lo que hace es mostrar lo que sabe haciéndolo. El discípulo aprende junto a él, porque aquí aprender no es imitar lo que el maestro hace, sino ejercitarse junto a él. El maestro no es un experto que sepa explicar y, por tanto, hacer comprender al discípulo. En cambio, el profesor es quien explica las reglas, los principios y las técnicas de una práctica que, muy posiblemente, él mismo no domine. Igual que el «alumno», el «individuo docente» es «invención exclusivamente humana. Enseñanza no es lo mismo que imitación de lo que se percibe en otros, 0 de lo que otro hace ante uno para que lo vea» (Blumenberg, 2004, 126). Esta creencia en la facultad de poder explicar, y por tanto en poder enseñar, se sostiene en la eficacia misma con que podemos alcanzar a explicar las reglas que por experiencia aprendemos, mostramos, pero no decimos. Es esa eficacia la que la condición de experto pretende transmitir y probar. Y por eso, como los sofistas y logógrafos, fundamos escuelas e instituciones donde se supone es posible perfeccionar lo que por experiencia ya se sabe.

Blumenberg dice lo mismo recurriendo a la imagen de la caverna, cuya fundación encontramos en Platón. La caverna, que en Platón funciona como el lugar donde los esclavos sólo perciben las apariencias de las cosas, es aquí un lugar protector donde encontrar seguridad frente a lo abierto e incierto del mundo. Cavernas hay muchas y el dilema es que, aunque en ellas podemos vivir, los víveres y el alimento están en el exterior, donde el individuo hace de verdad la experiencia, y donde cualquier cosa puede ocurrirle. La cultura 
es una de esas cavernas. Y por eso las cavernas se han llegado a convertir en «centros» de enseñanza y aprendizaje, «en lugar de origen de la primera institucionalización, profesionalización y codificación: grandes palabras para comienzos quizás mínimos» (Blumenberg, 2004, 1238). Lo que hay dentro de la caverna, aquello que se dice y que se explica, remite a lo que está fuera, pero no es la misma clase de experiencia: «El órgano de atención al mundo 'real' es ahí el 'se dice'. Esto conlleva que en la caverna había que enseñar a otros a crecer» (Blumenberg, 2004, 128). Parte de las justificaciones que pueden ofrecerse para la existencia de una educación, entendida ahora como una pedagogía de la caverna, se encuentra en el hecho de que los adultos, tras haber realizado su propia experiencia, la transmiten a los jóvenes para evitarles que tengan que recopilar la información necesaria para vivir. Esa transmisión proporciona un espacio de seguridad protector. Pero en ese acto de educación confluyen en realidad dos tipos de «experiencia»: la experiencia de realidad y la experiencia de transmisión de la realidad. Y, a medida que aumenta en el individuo docente su destreza para transmitir esa información, arrastra una mayor pérdida de realidad.

El incremento en la competencia disminuye la sensibilidad hacia la experiencia. Donde hay experimentum, no hay experiencia, donde hay regularidades no existen singularidades. El caso es que el material dado en educación es una experiencia por hacer. Y podemos aproximarnos al conocimiento de este material dado de la experiencia de dos formas. De modo cientifico, tratamos de fijar en la experiencia lo que en ella hay de regular, estable y repetible, lo que nos capacita para repetir una secuencia futura y reproducir así un determinado tipo de efectos previsibles. A través de un conocimiento poético, la experiencia puede ser abordada en su compleja síntesis y en su particular unicidad, para tratar de ver en ella lo que hay de único e irrepetible (Valente, 2002, 20-21). Aquí, lo de menos es lo que la experiencia contenga de constante sujeta a leyes 0 a reglas estables. Lo que importa es su carácter único, lo que hay en ella de no legislable y de irrepetible, lo que dibuja una línea que separa el antes y el después. 
Porque aprender significa reconocer que hay un tiempo (el «después») en el que sabemos lo que en un cierto «antes» ignorábamos. Sólo que en ese tiempo posterior no alcanzamos a recordar en qué instante aprendimos 10 que ahora creemos saber.

Es poéticamente como somos capaces de prestar atención de un modo especial: caemos en la cuenta sobre la singularidad de la experiencia. Llevada a su límite, ésta remite a una producción (poiesis): llevar algo, en este caso a alguien, a su presencia, a la visibilidad. «Producir» aquí no quiere decir fabricar, sino creación poética. Pues la producción (poiesis), como podemos leer en el Banquete, fue pensada como la actividad por la cual algo pasa de la nada al ser, a un modo de existencia concreta (Agamben, 1998, 116). Pero este significado original se ha ido perdiendo: la «producción» (poiesis) ha acabado siendo pensada como el proceso a través del cual se produce el objeto, donde el resultado objetivable marca el término de la actividad que lo produjo. El acento se ha puesto en el saber-hacer, más que en la experiencia del saber-expresar. Por eso lo que interesa hoy en educación es la destreza, la habilidad y la competencia. Porque el resultado de la educación no es ya una experiencia de formación, sino la capacitación para el mercado de trabajo, y quienes dictan los estándares de calidad no son otros que las propias empresas. En este saber hacer han ido tomando cada vez más protagonismo la figura del experto y la racionalidad de las instituciones que organizan esa práctica de la educación, entendida exclusivamente como proceso de escolarización en el entramado social (del mercado). Bajo una mentalidad fabricadora de este tipo, los acontecimientos dejan de tener especial interés. Se les arranca de su singularidad: sólo cuentan como medios para un objetivo previamente establecido.

El acontecimiento es lo que sobreviene en el tiempo, como tiempo humano, y lo que acaece en la determinación de la acción humana como experiencia y vivencia de ese tiempo. Siempre que ocurre algo nuevo irrumpe algo inesperado e imprevisible (Arendt, 1997, 64). Lo que introduce la noción de acontecimiento es el sentido, como algo diferenciado de la significación 
lógica. Si el «significado» trae cerrado e interpretado en un único sentido lo que dice, el sentido deja abierta la posibilidad a nuevas y múltiples significaciones de la realidad. Pensada desde la figura del acontecimiento, la reñexión sobre educación es un cierto saber poético. Aquí, lo poético es experiencia de apertura. Me refiero a un pensar que es, a la vez, una incisión poética (un nuevo sentido) y una incisión políitca (un nuevo comienzo). Lo poético introduce algo nuevo que rompe con lo anterior, algo nuevo que es sorpresa. El momento poético es un estado que implica una relación libre, no sometida a los significados dados y establecidos sobre las cosas. Y ello supone una libertad intensa del individuo en el mundo. Una libertad que es posibilidad de lo que hemos llamado insistentemente «comienzo». Lo poético en educación es la trama, el relato y la narrativa que nos ayuda en la tarea de inventarnos, allí donde ya sólo parece que podemos normalizar nuestras conductas, para ajustarlas al orden socialmente establecido. Inventarse quiere decir aquí reaprender la palabra y la imaginación poéticas, porque la voz poética trae a la conversación, a la práctica y al comienzo una expresión única, una voz propia que no es asimilable a ninguna otra. Por eso la voz poética es la voz más conversable de todas, más conversable que la de la ciencia. Aunque sea algo fulgurante e instantáneo, algo aparentemente insignificante y contradictorio, una relación poética es una relación liberadora. Porque es en lo poético donde lo instantáneo se detiene, donde la mirada capta el instante mismo de lo que sorprende, donde la educación, en fin, abandona las viejas y actuales pretensiones de conducir la mirada del otro en una dirección correcta, previamente definida, para convertirse en el acontecimiento de una mirada compartida.

La novedad que introduce la dimensión poética en la educación es sólo pensable como aquello que no tiene cualidades definidas y delimitables, y por eso introduce una relación de infinita extrañeza, la misma que se experimenta ante lo que no se puede dominar, algo que se resiste a la clasificación y la catalogación, porque no se deja fijar. Lo nuevo sólo existe en la mudanza y en el devenir, y por eso expresa la posibilidad del inicio 
como diferenciación. Lo nuevo es, pues, del orden del acontecimiento, que rompe la lógica encadenada de* los hechos y las relaciones causales 0 establecidas como inamovibles. Como en otros ámbitos, una de las tareas centrales de lo poético en la educación es la de favorecer la alteración del orden de las cosas. No se trata sólo de que a través de la educación hagamos lo posible para atenernos a las grandes palabras — como «humanidad», «bondad», «tolerancia» — vocablos cada vez más elusivos, sino de lanzarse en las mutaciones decisivas de una pluralidad aceptada como tal.

\section{La educación y el arte de la conver sación}

La sección universitaria del así llamado «espacio educativo europeo» (inseparable de un espacio universitario casi totalmente mundializado) se está configurando como una enorme red de comunicación entre investigadores, expertos, profesionales, especialistas, estudiantes y profesores. Constantemente se constituyen grupos de trabajo, redes temáticas, núcleos nacionales e internacionales de investigación y de docencia. La información circula, las personas viajan, el dinero abunda, las publicaciones se multiplican. Proliferan los encuentros de todo tipo y, con ellos, las oportunidades para el intercambio, para la discusión, para el debate, para el diálogo. Por todas partes se fomenta la comunicación. Las actividades universitarias de producción y de transmisión de conocimiento se planifican, se homologan y se coordinan masivamente. Y todos los días se nos invita a hablar y a escuchar, a leer y a escribir, a participar activamente en esa gigantesca maquinaria de fabricación y de circulación de informes, de proyectos, de textos. La pregunta es: ¿en qué lengua? Y también: ipuede ser esa lengua nuestra lengua?

Al preguntar ¿en qué lengua? no me refiero al español, al francés, al inglés 0 al esperanto. Con esa pregunta sólo trato de llamar tu atención sobre la 
importancia del lenguaje y apelar a tu capacidad para distinguir las distintas lenguas que pueden existir en una lengua, en cualquier lengua. Te recuerdo, entonces, lo que seguramente ya sabes, eso que, si no lo sabes, aunque sea oscuramente, difícilmente te podré explicar: que el lenguaje no es sólo algo que tenemos sino que es casi todo lo que somos, que determina la forma y la sustancia no sólo del mundo sino también de nosotros mismos, de nuestro pensamiento y de nuestra experiencia, que no pensamos desde nuestra genialidad sino desde nuestras palabras, que vivimos según la lengua que nos hace, de la que estamos hechos. Y ahí el problema no es sólo qué es lo que decimos y qué es lo que podemos decir, sino también, y sobre todo, cómo lo decimos: el modo como distintas maneras de decir nos ponen en distintas relaciones con el mundo, con nosotros mismos y con los otros.

Yo he aprendido eso de algunos amigos especialmente sensibles a lo que podríamos llamar la forma de la verdad. Ellos me han enseñado a leer atendiendo no tanto al contenido doctrinario de los distintos filósofos y de las distintas filosofías como a sus opciones formales. $Y$ a ver en esas opciones profundas consecuencias éticas y políticas. Podría hablarte de Platón, de su opción por el diálogo o de su crítica a la escritura, de Montaigne y de la invención del ensayo, de Nietzsche y de su oposición a las formas dogmáticas, periodísticas y profesorales de la filosofía, de Kierkegaard respondiendo al pensar sistemático de Hegel, de Foucault y de su concepción de la crítica como un trabajo permanente de desujección de la red que tejen la verdad y el poder, tanto por el lado de la verdad del poder como por el lado del poder de la verdad. Pero no quiero darte bibliografía (nada sería más imbécil que decirte lo que deberías leer) ni mucho menos colocar mis palabras bajo alguna autoridad. Lo único que pretendo es contarte que, a mí, todos ellos me han enseñado muchas cosas y muy importantes, pero que me han enseñado, sobre todo, a afinar el oído. Algo que me han enseñado también varios poetas y algunos narradores. $Y$ muchas personas de mi mismo oficio para las cuales el hablar y el escuchar, 
el leer y el escribir, no es una herramienta que se domina con mayor 0 menor habilidad sino un problema en el que se juegan cosas mucho más graves que la eficacia de la comunicación.

Desde ahí, lo único que intento es decirte que al preguntar por la lengua en la que se constituye esa gigantesca red de comunicación en la que, según dicen, todos deberíamos participar, te estoy invitando a que pongas en juego tu propio oído lingüístico, tu propia sensibilidad al modo como algunas formas de escribir y de leer, de hablar y de escuchar, extienden la sumisión, el conformismo, la estupidez, la arrogancia y la brutalidad.

Por otra parte, al preguntar si esa lengua puede ser la nuestra no estoy hablando de mi lengua ni de la tuya, ni tampoco de alguna lengua que podría ser común para ti y para mí. Yo no sé quién eres, ni mucho menos cuál es tu lengua. En lo que respecta a la mía, lo único que sé es que la estoy buscando cada vez que hablo 0 que escribo 0 que escucho 0 que leo y que, en cualquier caso, nunca seré yo quien la encuentre. Además, he aprendido a desconfiar de cualquier «nosotros» enunciado con la pretensión de incluirme en cualquier identidad posicionai de tipo nosotros los profesores, nosotras las mujeres, nosotros los filósofos, nosotros los europeos, nosotros los intelectuales, nosotros los críticos, nosotros los jóvenes, nosotros los que tenemos algo en común. Cuando oigo alguno de esos «nosotros», me dan ganas de levantar la mano y de decir que yo no tengo nada que ver con eso.

Lo que quiero decirte es que, cuando leo lo que circula por esas redes de comunicación u oigo lo que se dice en esos encuentros de especialistas, la mayoría de las veces tengo la impresión de que ahí funciona una especie de lengua de nadie, una lengua neutra y neutralizada de la que se ha borrado cualquier marca subjetiva. Entonces, lo que me pasa es que me dan ganas de levantar la mano y de preguntar ¿hay alguien ahí? Además, siento también que esa lengua no se dirige a nadie, que construye un lector 0 un oyente totalmente abstracto e impersonal. Una lengua sin sujeto sólo puede ser la lengua de unos sujetos sin lengua. Por eso tengo la sensación de que esa lengua no tiene nada que ver con nadie, no sólo contigo o conmigo sino 
con nadie, que es una lengua que nadie habla y que nadie escucha, una lengua sin nadie dentro. Por eso no puede ser nuestra, no sólo porque no puede ser ni la tuya ni la mía, sino también, y sobre todo, porque no puede estar entre tú y yo, porque no puede estar entre nosotros.

No hay políticas de la verdad que no sean, al mismo tiempo, políticas de la lengua. Los aparatos de producción, legitimación y control del conocimiento son, indiscerniblemente, aparatos de producción, legitimación y control de ciertos lenguajes. Iniciarse en un área del saber es, fundamentalmente, aprender sus reglas lingüísticas: aprender a hablar, a escuchar, a leer y a escribir como está mandado. Pertenecer a una comunidad científica 0 a una comunidad de especialistas (si es que esos montajes institucionales merecen el nombre de comunidades) supone haber interiorizado sus vocabularios y sus gramáticas, manejar correctamente sus reglas de construcción y de interpretación de enunciados, saber usar los lenguajes de la tribu.

Pero si una lengua es un dispositivo de acogida y de pertenencia, también es un dispositivo de rechazo y de exclusión: de aquellos que no la dominan, que no la aceptan, que no se sienten a gusto en ella, que no la usan, que no se someten a sus reglas, que no obedecen sus imperativos.

Detengámonos un momento en el ocultamiento sistemático de esas políticas de la lengua que son constitutivas de todas las políticas de la verdad. Habrás notado que, en la Universidad, sobre todo en aquellos niveles en que los estudiantes se inician en la investigación y/o en la producción de conocimiento, es decir, en la fabricación de textos legítimos, se problematiza intensamente el método, pero no la lectura ni la escritura. Y tal vez para ti, como para mí, los mayores quebraderos de cabeza estén relacionados justamente con la lectura y con la escritura. Lo que de verdad nos preocupa es qué y cómo leer y qué y cómo escribir. Sabemos que es por ahí por donde pasan las opciones más importantes. Pero de eso nadie habla. Como si se diera por supuesto que, llegados a ese nivel, todo el mundo ya supiera leer y escribir y que, si no sabe, lo único que hay que hacer es mejorar las competencias instrumentales de expresión y de comprensión. Como si leer 
no fuera otra cosa que capturar la información (ideas, datos, noticias, etc.) contenida en un texto y como si escribir no fuera otra cosa que poner sobre el papel lo que uno ya sabe, la información o el conocimiento que uno ha obtenido antes y en otro lugar que en la escritura. Sin embargo, el que la lectura y la escritura no se problematicen explícitamente, el hecho de que, al menos aparentemente, ni la lectura ni la escritura sean un problema, no significa que no sean el lugar de potentísimos mecanismos de control. Si no fuera por esos mecanismos sería imposible la imposición generalizada y la posterior naturalización de esa lengua de nadie.

En las últimas décadas se han configurado dos lenguajes dominantes en el campo educativo: el lenguaje de la técnica y el lenguaje de la crítica. La pedagogía continúa escindida entre los así llamados tecnólogos y los así llamados críticos, entre los que construyen la educación desde el par ciencia/técnica, como una ciencia aplicada, y los que la construyen desde el par teoría/práctica, como una praxis reflexiva.

El primer lenguaje es el de los científicos, los que se sitúan en el campo educativo desde la legitimidad de la ciencia y de la planificación técnica, los que usan ese vocabulario de la eficacia, de la evaluación, de la calidad, de los resultados, de los objetivos; el lenguaje de los didactas, los psicopedagogos, los tecnólogos, los que construyen su legitimidad a partir de su cualidad de expertos; el lenguaje de los que saben, de los que se sitúan en posiciones de poder a través dé posiciones de saber.

El segundo lenguaje es el de los críticos, los que se sitúan en el campo desde la legitimidad de la crítica, los que usan ese vocabulario de la reflexión sobre la práctica 0 en la práctica; el lenguaje de los que consideran la educación como una praxis política encaminada a la realización de ciertos ideales como la libertad, la igualdad o la ciudadanía, y de los que critican la educación en tanto que produce sumisión y desigualdad, en tanto que destruye los vínculos sociales; el lenguaje de los que se sitúan en posiciones de poder a través de convertirse en portavoces de esos ideales constantemente desmentidos, una y otra vez desengañados. 
Entre esas dos lenguas se configuran todas las doxas que constituyen el sentido común pedagógico. Por un lado, la lengua en la que se enuncia 10 que nos dicen que hay, lo que nos dicen que es: esa lengua en la que parece que es la realidad la que habla... aunque ya sabemos que se trata de la lengua que hablan los fabricantes, los dueños y los vendedores de realidad. Por otro lado, la lengua en la que se enuncia lo que nos dicen que debería haber, lo que nos dicen que debería ser: esa lengua de las posibilidades, de las finalidades, de las intenciones, de los ideales, de las esperanzas... aunque ya sabemos que se trata de la lengua que hablan los que producen y venden ideales, los propietarios del futuro. El lenguaje de la realidad y el lenguaje del futuro. 0 , dicho de otro modo, el lenguaje de los que hablan en nombre de la realidad y de los que hablan en nombre del futuro. $\mathrm{Y}$, entre la realidad y el futuro, la práctica como punto de paso obligatorio entre lo que es y lo que debería ser. Puesto que la educación, según dicen, debe partir de la realidad, el campo pedagógico es un gigantesco dispositivo de producción de realidad, de una cierta realidad. Como la educación, según dicen, debe transformar lo que hay a través de su propia transformación, el campo pedagógico fabrica incansablemente proyectos para la práctica, para una cierta práctica. Nuestra lengua, nos dicen, tiene que ser a la vez realista, práctica y progresista. Si hablamos alguna variante de ese lenguaje que elabora constantemente proyectos para la acción trazando puentes entre hechos (verdaderos) sobre lo que es y (buenas) intenciones sobre lo que debería ser tendremos un lugar seguro y asegurado en el campo. Pero ese lenguaje nos parece vacío y se nos está haciendo impronunciable.

Cuando digo que ese lenguaje parece vacío, me refiero a la sensación de que se limita a gestionar adecuadamente lo que ya se sabe, lo que ya se piensa, lo que, de alguna forma, se piensa sólo, sin nadie que lo piense, casi automáticamente. Me refiero a esa sensación de que tanto los técnicos como los críticos ya han dicho lo que tenían que decir y ya han pensado lo que tenían que pensar. Podría decirse que tanto sus vocabularios como sus gramáticas están ya constituidos y fijados aunque, obviamente, aún sigan 
siendo capaces de enunciados distintos y de ideas novedosas. Una gramática es una serie finita de reglas de producción de enunciados susceptible de una productividad infinita. Y cuando una gramática está ya constituida, cualquier cosa que se produzca en su interior da una sensación de «ya dicho», de «ya pensado», una sensación de que pisamos terreno conocido, de que podemos seguir hablando o pensando en su interior sin esfuerzo, sin dificultades, sin sobresaltos, sin sorpresas, casi sin darnos cuenta.

Cuando digo que ese lenguaje se está haciendo impronunciable, me refiero, por ejemplo, a su carácter totalitario, al modo como convierte en obligatorias tanto una cierta forma de la realidad (junto con la forma de la verdad que es su correlato) como una cierta forma de la acción humana. También a su arrogancia, al modo como convierte en legítima una cierta posición enunciativa en la que siempre se habla desde arriba (o desde ningún lugar, que para el caso es lo mismo) y en la que el sujeto de la enunciación se constituye en la pretensión de definir el mundo y de transformarlo. Por último, a esa sensación de que se trata de un lenguaje de aspirantes, si no a filósofo-rey, al menos a alguna de sus versiones degradadas: intelectual universal, conciencia crítica, portavoz autorizado 0 , simplemente, funcionario o burócrata con inclinaciones político-administrativas.

Si habláis ese lenguaje, nos dicen, hablaréis desde la realidad. Primero la inventaréis, luego la impondréis, y finalmente os podréis apoyar en ella. Entonces, la realidad, con toda su fuerza, su prestigio, su solidez y su autoridad, estará de vuestro lado. Pero a nosotros esa realidad nos produce una extraña sensación de irrealidad. Como si no tuviera densidad, cuerpo, como si al presentarse como una realidad abstracta, transparente y bien ordenada, nos apartara de la experiencia que es siempre situada, concreta, confusa, singular. Como si sospechásemos que esa manera de ver, de comprender 0 de objetivar lo que hay tuviera su propia ceguera constitutiva, nos impidiera ver y oír, nos hiciera sordos, nos convirtiera en incapaces de tocar el mundo de otra forma que no sea haciéndole violencia. Además, no esta claro que lo que hay sea lo que nos dicen que hay. Ya no confiamos 
en los que nos dicen qué es lo real y cómo es el mundo. Ya no nos fiamos de los que pretenden hablar desde ningún lugar, de los que sólo pueden hablar en general, sin ser ellos mismos los que hablan. A lo mejor lo que necesitamos no es una lengua que nos permita objetivar el mundo, una lengua que nos dé la verdad de lo que son las cosas, sino una lengua que nos permita vivir en el mundo, hacer la experiencia del mundo, y elaborar con otros el sentido (o el sin-sentido) de lo que nos pasa.

Si habláis ese lenguaje, nos dicen, tendréis una relación activa con el mundo 0 , lo que es lo mismo, una relación con el futuro. Pero nosotros tenemos problemas con esa forma de entender la acción y, sobre todo, con ese futuro. En primer lugar, porque tenemos la sensación de que el modo en que se diseña ese futuro forma parte de las convenciones del presente, de que ese lenguaje de las alternativas se ajusta demasiado bien al lenguaje de la planificación, que es un lenguaje de estado, y al lenguaje de la innovación, que es un lenguaje de mercado. Además, sabemos, quizá confusamente, que no podemos fiarnos de los que inmediatamente saben qué es lo que hay que hacer para que las cosas sean de otra manera, y mucho menos de los que dicen, sin avergonzarse, qué es lo que los demás deberían hacer. A lo mejor lo que necesitamos no es una lengua en la que enunciar nuestros poderes 0 nuestras impotencias, 0 en la que dar forma a nuestra buena voluntad, 0 en la que tranquilizar nuestra buena conciencia, sino una lengua que nos permita compartir con otros la incómoda perplejidad que nos causa la pregunta ¿qué hacer? o las infinitas dudas y cautelas con las que hacemos lo que hacemos.

Si habláis ese lenguaje, nos dicen, hablaréis desde la autoridad del saber, seréis inteligentes. Pero nosotros tenemos problemas con ese saber y con esa inteligencia y sentimos, quizá oscuramente, que no son de fiar. Frente a los que hablan movilizando saberes, parecemos sin duda más tontos, más ignorantes. Nuestra lengua es más insegura, más balbuceante. No leemos lo que todo el mundo lee, o lo que todo el mundo simula que ha leído. No queremos escribir como todo el mundo escribe. Muchas de las palabras 
sagradas de la tribu nos parecen banales, vacías y, por tanto, impronunciables. Cada vez borramos más palabras de nuestro vocabulario, como si ya no pudiéramos usarlas. A veces usamos palabras extrañas. No queremos que se nos entienda de inmediato. Y sólo somos capaces de escuchar a aquellos a 401 los que no entendemos, a aquellos de los que no sabemos inmediatamente qué es lo que dicen y qué es lo que quieren decir.

Si habláis ese lenguaje, nos dicen, seréis comprendidos por todos, tendréis un lugar en esa especie de comunidad universal de habla en la que las palabras y las ideas circulan legítimamente y sin problemas. Pero nosotros tenemos problemas con esa comprensión y, sobre todo, con ese todos. No queremos que se nos comprenda, sino que se nos escuche, y somos capaces de ofrecer, a cambio, nuestra capacidad para escuchar lo que quizá no comprendemos. Además, no queremos hablar para todos, porque sabemos que ese todos es, en realidad, nadie. No nos fiamos de esa lengua de-subjetivada que no tiene a nadie dentro, de esa lengua de nadie, de esa lengua que hablan los que no tienen lengua. No queremos esa lengua de-subjetivante que no se dirige a nadie, que parece que sólo habla para sí misma. Sabemos que hablar y escribir, escuchar y leer, sólo son posibles por uno mismo, con otros pero por uno mismo, en primera persona, en nombre propio; que siempre es alguien el que habla, el que escucha, el que lee y escribe, el que piensa. Además, si es verdad que se puede debatir 0 dialogar con cualquiera, si es verdad, incluso, que se puede argumentar con cualquiera, sólo a cada uno concierne con quién quiere hablar y con quién puede pensar.

Si uso el «nosotros» para decir que tenemos problemas con esa realidad, con esa forma de la acción, o con ese saber es, de nuevo, porque quiero apelar a esa sensación de que, en ese lenguaje, se produce una realidad de nadie, una acción de nadie y un saber de nadie. Ahí, en ese lenguaje, no hay nadie dentro de la realidad, ni dentro de la acción, ni dentro del saber. Por eso ni la realidad, ni la acción ni el saber pueden estar entre nosotros. Ese «nosotros» no pretende otra cosa que señalar hacia un lenguaje en el 
que podamos hablarnos. Un lenguaje que trate de decir la experiencia de la realidad, la tuya y la mía, la de cada uno, la de cualquiera, esa experiencia que es siempre singular y, por tanto, confusa, paradójica, inidentificable. Y lo mismo podríamos decir de la experiencia de la acción, la de cada uno, la de cualquiera, la que no puede hacerse sino apasionadamente y en medio de la perplejidad. Y de la experiencia del saber, la de cada uno, la de cualquiera, la que no quiere tener otra autoridad que la de la experimentación y la incertidumbre, la que siempre conserva preguntas que no presuponen las respuestas, la que está apasionada por las preguntas.

Necesitamos un lenguaje para la conversación. No para el debate, o para la discusión, o para el diálogo, sino para la conversación. No para participar legítimamente en esas enormes redes de comunicación e intercambio cuyo lenguaje no puede ser el nuestro, sino para ver hasta qué punto somos aún capaces de hablarnos, de poner en común lo que pensamos o lo que nos hace pensar, de elaborar con otros el sentido o el sinsentido de lo que nos pasa, de tratar de decir lo que aún no sabemos decir y de tratar de escuchar lo que aún no comprendemos. Necesitamos una lengua para la conversación como un modo de resistir al allanamiento del lenguaje producido por esa lengua neutra en la que se articulan los discursos científico-técnicos, por esa lengua moralizante en la que se articulan los discursos críticos, y, sobre todo, por esa lengua sin nadie dentro y sin nada dentro que pretende no ser otra cosa que un instrumento de comunicación. Necesitamos una lengua para la conversación porque sólo tiene sentido hablar y escuchar, leer y escribir, en una lengua que podamos llamar nuestra, es decir, en una lengua que no sea independiente de quién la diga, que a ti y a mí nos diga algo, que esté entre nosotros.

Si uso la palabra «conversación» para decirte, otra vez, que quiero hablar contigo, es porque esa palabra sugiere horizontalidad, oralidad y experiencia. Lo que quiero decirte entonces, en primer lugar, es que necesitamos buscar una lengua que no rebaje, que no disminuya, que no construya posiciones de alto y bajo, de superior e inferior, de grande y pequeño. Necesitamos 
una lengua que nos permita una relación horizontal, una relación en la que tú y yo podamos sentirnos del mismo tamaño, a la misma altura.

Lo que quiero decirte, en segundo lugar, es que necesitamos una lengua que no sea sólo inteligible. Fíjate que cuando en filosofía, y no sólo en filosofía, se trata de dar cuenta del carácter sensible de la lengua, cuando se trata de considerar la lengua desde su relación con el cuerpo y con la subjetividad, frecuentemente se apela a nociones que tienen que ver con la oralidad, con la boca y con la lengua, con el oído y con la oreja, con la voz. Y ahí no se trata de la diferencia entre habla y escritura, sino de la diferencia entre distintas experiencias de la lengua incluyendo el leer y el escribir. La oralidad a la que me refiero no se opone a la escritura sino que atraviesa todo el lenguaje, como si la escritura tuviera su propia oralidad, como si pudieran trazarse diferencias entre tipos de escritura según sus distintas formas de oralidad. La voz es la marca de la subjetividad en la experiencia del lenguaje, también en la experiencia de la lectura y de la escritura. En la voz, lo que está en juego es el sujeto que habla y que escucha, que lee y que escribe. A partir de aquí se podría establecer un contraste entre una lengua con voz, con tono, con ritmo, con cuerpo, con subjetividad, una lengua para la conversación... y una lengua sin voz, afónica, átona o monótona, arrítmica, una lengua de los que no tienen lengua, una lengua de nadie y para nadie que sería, quizá, esa lengua que aspira a la objetividad, a la neutralidad y a la universalidad y que intenta, por tanto, el borrado de todo trazo subjetivo, la indiferencia tanto en lo que se refiere al hablante/escritor como en lo que se refiere al oyente/lector.

Y lo que quiero decirte, por último, es que necesitamos una lengua en la que hablar y escuchar, leer y escribir, sea una experiencia. Singular y singularizadora, plural y pluralizadora, activa pero también pasional, en la que algo nos pase, incierta, que no esté normada por nuestro saber, ni por nuestro poder, ni por nuestra voluntad, que nunca sepamos de antemano a dónde nos lleva. Me gustaría conversar contigo. 


\section{La educación y la experiencia de la finitud}

Una pedagogía de la finitud parte de la idea de que los seres humanos somos ineludiblemente seres en el mundo y, por lo mismo, con los demás, para los demás y frente a los demás. Es lo que quiero expresar con el término situación. Querámoslo o no, cada uno de nosotros es ineludiblemente un ser en situación y, por lo mismo, en relación con los otros. En otros lugares ya he manifestado la firme convicción de que los seres humanos no pueden eludir su «condición adverbial». Esto significa que las situaciones son el espacio y el tiempo (quizá deberíamos escribir en plural «espacios y tiempos») en los que vivimos, pensamos, actuamos, nos relacionamos, nos experimentamos como seres corpóreos. No hay, ni podrá haber nunca, una especie de «situación en general» 0 «en abstracto», como tampoco puede existir «el Hombre» 0 «la Mujer», 0 incluso «el Bien» 0 «la Belleza», 0 «la Justicia». El «Yo puro» no existe, como no existe la «Razón pura».

El punto de partida de una pedagogía de la finitud como la que intento esbozar radica en los seres humanos de carne y hueso que, para decirlo con Unamuno, nacen, viven, sufren y mueren, sobre todo mueren. Hombres y mujeres son seres corpóreos 0 , si se prefiere, seres situados y situándose (Rombach, 2004). No tenemos acceso a nosotros mismos, al mundo y a los demás, si no es a través de las múltiples situaciones, de los (in)finitos contextos en los que en cada instante vamos (re)construyendo nuestras vidas. Es por esta razón que resulta inseparable la situación de la interpretación. Precisamente porque la situación es ineludible, porque no hay «pureza» en la vida humana, porque «no hay texto sin contexto», nos encontramos en la necesidad de interpretar, es decir, de contextualizar, de reelaborar, de decir y de volver a decir, de desdecirnos, de leer y de releer. Esta es una tarea inacabable porque toda situación es finita, porque toda situación es provisional y ambigua.

Una pedagogía como la que presento se autocalifica de narrativa, o si se quiere de antimetafísica, entendiendo por «metafísica» el trayecto inaugurado 
por Platón en el Fedón (99 c-d) en la conocida metáfora de la «segunda navegación». Dicho de forma clara y breve: en esta metáfora se inicia el périplo metafísico más importante de la historia de la filosofía occidental. Este itinerario consiste en suponer que «detrás» del mundo que vemos, olemos, tocamos... existe un ser meta-empírico, supra-sensible y trascendente. En otras palabras, hay metafísica desde el momento en que se considera que el ser no se reduce al ser sensible, sino que hay otro ser, más real que el primero, verdaderamente real, que se halla más allá de lo sensible. Esta idea de Platón constituye la piedra de toque de la filosofía occidental con unas consecuencias impresionantes para la ética y la educación. A diferencia de una «filosofía metafísica», mi posicionamiento (que puede llamarse «narrativo» 0, simplemente «antropológico») sostiene que somos finitos, que la finitud, la contingencia y la ambigüedad resultan condiciones de posibilidad de la(s) vida(s) humana(s). En todo momento estamos «situándonos»y, por lo tanto, nunca podemos dejar de ser positiva 0 negativamente «en-relación-con», «en-referencia-a». En definitiva: una pedagogía de la finitud parte del supuesto de que la existencia humana es un trayecto histórico que no puede ser «capturado» por un pensamiento esencialista y apriorístico, por un discurso substancialista.

En el marco de una pedagogía de la finitud la ética ocupa un lugar privilegiado. Pero ¿qué es la ética? ¿Por qué sostengo que la educación es constitutivamente ética? Es necesario aclarar que para una pedagogía de la finitud, la ética no tiene nada que ver con la deontologia, con las normas o los imperativos. La ética es el modo como los seres humanos nos relacionamos con los demás, es la respuesta responsable que cada hic et nunc ofrecemos al otro. Desde la perspectiva de una pedagogía de la finitud, hay ética porque los seres humanos somos seres sensibles, estamos abiertos a un mundo incierto, a unas relaciones con los demás y con nosotros mismos, que no se pueden resolver a priori. Hay ética porque, como ha señalado con mucho acierto Zygmunt Bauman, hay imprevisibilidad y ambigüedad (Bauman, 2002). A menudo se cree que la ética sufre en condiciones de incertidumbre, pero para una pedagogía de la finitud la 
incertidumbre, la contingencia y la ambigüedad resultan imprescindibles. Si todo fuera «claro y distinto» (0 dicho de otro modo, si se hiciera realidad el ideal cartesiano), la ética no solamente sería inútil sino imposible. Hay ética porque los seres humanos no somos ni ángeles ni bestias y porque quien hace el ángel hace la bestia (Pascal). En definitiva: la ética es posible porque los seres humanos no somos ni buenos ni malos por naturaleza, sino radicalmente ambiguos, es decir, culturales, históricos, situacionales. «Si todo es natural, no hay sitio para la moral», escribe Octavio Paz (Paz, 2003, 649). Desde este punto de vista, una pedagogía de la finitud, es decir, una pedagogía que tiene sus condiciones de posibilidad en los múltiples contextos y situaciones de los seres humanos en sus mundos, cree que las acciones educativas son constitutivamente éticas, esto es, que la ética no se halla al final de la acción educativa, sino al comienzo. Una pedagogía de la finitud está convencida que la ética es «relación». Una educación al margen de la ética sería imposible. En tal caso nos encontraríamos en un acto «fabricador», «adoctrinador». Como insinuaba antes, por tanto, hay que tener muy presente que no entiendo la ética como la atención a un «deber» puro, impersonal, universal, fruto de un factum de la razón pura práctica (el imperativo categórico de Kant), sino como una relación responsable con los otros. De ahí también que no haya ética sin sentimientos porque sin sentimientos no hay modo de ser en relación con los otros, con el mundo y con nosotros mismos.

Ahora bien, hhay algún tipo de relación que muestre especialmente la ética? Es aquí el momento de acudir a la bella imagen de Octavio Paz. La ética es una relación de compaña. La compatía es un sentimiento que consiste en «la participación en el sufrimiento del otro» (Paz, 2003, 600). Precisamente porque somos capaces de vivir el sufrimiento y la muerte del otro, la ética es posible. En otros lugares, apoyándome en una interesante intuición del filósofo lituano Emmanuel Levinas, he expresado esta misma idea con otras palabras: la ética sería una relación de «no indiferencia» hacia el otro 0, si se quiere, una relación de «deferencia». 
En cierta ocasión Max Horkheimer hablaba de la «teología» como de un deseo, de un anhelo, del anhelo de que el verdugo no triunfe definitivamente sobre la víctima inocente, del anhelo de que ni el mal ni la muerte tendrán la última palabra (Horkheimer, 2000, 169). Pues bien, esta sería otra forma de entender la ética, como un deseo, como un anhelo. Para una pedagogía de la finitud la ética se presenta como una «ética negativa», en el sentido de Horkheimer 0, si se prefiere, de Zygmunt Bauman. En sus conversaciones con Keith Tester, Bauman sostiene que «si sabes cómo es exactamente la sociedad buena, cualquier crueldad que cometas en su nombre quedará perdonada y justificada. Sólo podemos ser buenos los unos con los otros, absteniéndonos de toda crueldad, cuando no estamos seguros de nuestra sabiduría y admitimos la posibilidad de un error (Bauman, 2002, 73).

La ética se activa en el instante en que se vive la experiencia del mal, del horror, de lo demoníaco (Paul Tillich). Sin una sensibilidad frente a la experiencia del mal, sin que esto suponga la «tentación del bien» (Todorov), la ética no tiene ningún sentido. Bauman advierte que «aparte de la esperanza de que el mal desaparezca total 0 parcialmente, no estamos seguros que lo que pueda reemplazarlo sea bueno» (Bauman, 2002, 69). Hay que desconfiar de todas las éticas que hablan en nombre del Bien, de todas las éticas que creen conocer «el Camino» hacia la Verdad. Todas ellas resultan sumamente peligrosas. Por mi parte diría, con Nietzsche, que el Camino no existe (Nietzsche, 1979, 272). Lo que hay, lo que los seres humanos tenemos, sólo son tentativas, senderos, trayectos, sendas perdidas, caminos que no conducen a ninguna parte... En definitiva, que «ser moral significa no sentirse nunca lo suficientemente bueno», (Bauman, 2002, 69) 0 también, para decirlo con Jacques Derrida: «prohibido el reposo a cualquier forma de buena conciencia» (Derrida, 1995, 9). Por esta razón, una pedagogía de la finitud no aspira a una «sociedad buena» 0 a una «sociedad justa», es decir, a una «ciudad ideal», a una especie de «paraíso terrenal». No; a lo sumo se anhela una sociedad decente, tal como la ha dibujado el filósofo judío Avishai Margalit. Una sociedad decente es aquella que no humilla a 
sus integrantes, es aquella cuyas instituciones no humillan a las personas (Margalit, 1997, 15). Margalit define la sociedad decente negativamente, y lo hace por varias razones. Entre ellas por un motivo ético: existe una notable asimetría entre erradicar el mal y fomentar el bien. Es más prioritario eliminar males dolorosos que crear bienes disfrutables. En este marco no cabe duda, pues, que la sensibilidad ocupa un lugar privilegiado. Desde mi punto de vista los «conceptos» (por llamarlos de alguna manera) de la ética son términos sensibles. Sin sensibilidad uno se ve forzado a preguntarse: ¿por qué debo ser moral? Pero esta pregunta, como señala Bauman, es el fin y no el origen de la ética (Bauman, 2002, 80).

Una pedagogía de la finitud es, en definitiva, una pedagogía del tacto. Quizá sea conveniente — siguiendo al pedagogo holandés Max van Manen - comenzar distinguiendo entre tacto y táctica. Desde un punto de vista etimológico táctica deriva del griego antiguo taktiké y hace referencia a una «estrategia militar», al talento del general que sabe mover a sus tropas con acierto en el campo de batalla. El tacto nada tiene que ver con la táctica. Es más, es lo contrario de la táctica. Tacto deriva del latín tactus y significa tocar (tangere). El tacto es esencialmente implanificable. Así, como señala Max van Manen: «Tener tacto es ser solícito, sensible, perceptivo, discreto, consciente, prudente, juicioso, sagaz, perspicaz, cortés, considerado, precavido y cuidadoso. ¿Sería mala alguna de estas características en un educador?» (Van Manen, 1998, 138).

Así pues, es muy interesante contraponer una «pedagogía de la táctica» a una «pedagogía del tacto»y, por lo tanto, de la sensibilidad. Los pedagogos que aplican una pedagogía de la táctica consideran que su labor es buena en la medida en que son capaces de desarrollar un «plan de acción». La táctica tiene unas connotaciones de supervisión, de planificación, de estrategia, de esquema, de programa, de proyecto, de diseño... Una pedagogía del tacto, en cambio, es una pedagogía de la responsabilidad, de la oportunidad, de la ocasión, del arte de la improvisación, es una pedagogía que sabe tratar a cada persona como seres singulares, únicos e irrepetibles. Max van Manen 
lo explica con suma precisión: «La solicitud y el tacto pedagógicos son dos conceptos que guardan una estrecha relación. Alguien que habitualmente sea solícito es más probable que demuestre ser una persona con tacto en una determinada situación que alguien que se muestre relativamente desconsiderado. Parece que la solicitud pedagógica es una capacidad reflexiva que nace de la reflexión detenida sobre las experiencias pasadas. Y ahora, en la inmediatez de tener que actuar en este momento, el énfasis se pone en «sentir» qué es lo importante en esta situación concreta. La solicitud y el tacto pedagógicos dependen de la capacidad cultivada de percibir y escuchar a los jóvenes. Pero el tacto en la enseñanza no es una simple destreza. Al contrario, se podría definir como una «preparación para la improvisación» (Van Manen, 2004, 49). Una pedagogía de la finitud es, ante todo y sobre todo, una pedagogía de la atención, del cuidado, de la sensibilidad. El pedagogo sabe que cada situación es distinta, que cada contexto es diferente $y$, por lo tanto, que hay momentos en los que no le queda más remedio que ser cuidadoso, deferente.

El pedagogo descubre fácilmente que la enseñanza no es un simple empeño técnico. En otras palabras: los pedagogos saben que las situaciones verdaderamente difíciles y realmente importantes no pueden resolverse técnicamente, esto es, aplicando un «conocimiento de experto». Me refiero obviamente a las situaciones que hacen referencia a la contingencia, es decir, a aquellas preguntas que implican la vida humana en su totalidad 0, mejor todavía, el sentido de la vida: el nacimiento, el amor, el mal, el sufrimiento, la muerte... Las situaciones contingentes son «situaciones laberínticas» inseparables del modo de ser de los seres humanos en sus mundos, situaciones que no pueden resolverse acudiendo a la figura del experto. Para decirlo con Hans-Georg Gadamer, las situaciones contingentes son «resistentes a cualquier tipo de ilustración». Del laberinto puede salirse, pero siempre provisionalmente. Nadie está nunca del todo libre de estas situaciones, y creo que una tarea fundamental de la pedagogía actual debería ser precisamente ésta: considerar qué posibles salidas (provisionales) existen 
0, en otras palabras, qué «praxis de dominio de la contingencia» (Duch 1997) pueden descubrirse en un mundo como el que nos ha tocado vivir. Para ello es fundamental el clima, la atmósfera, la calidad de la relación entre unos y otros, calidad que no viene dada fundamentalmente por lo que se dice 0 se hace, sino por el cómo se dice 0 cómo se hace, es decir, por el tacto y por el tono.

Evidentemente una posición como la que estoy defendiendo resulta incómoda para muchos pedagogos y educadores. La razón es obvia: la atmósfera de una situación es un fenómeno complejo. «Un lugar que a un niño le parecerá amenazador y le intimidará a otro niño le encantará como algo estimulante y lleno de aventuras» (Van Manen, 2004, 73). № hay manera de establecer a priori qué comportamiento es el adecuado en estas situaciones. Una pedagogía del tacto, de la sensibilidad, no es una «pedagogía de la receta», porque la vida, toda vida humana, no lleva, ni puede llevar consigo un «manual», unas «instrucciones de uso» (Perec). Nadie puede decidir a priori qué es lo que se debe hacer en una situación puesto que todas las situaciones, como todas las personas, son distintas. Vivimos, para decirlo con Milán Kundera en La insoportable levedad del ser, en el «planeta de la inexperiencia». Los seres humanos lo vivimos todo como si fuera la primera vez y sin ninguna preparación. La vida parece un esbozo, aunque quizá tampoco sea ésta la palabra correcta, porque «esbozo» es siempre un «esbozo de algo», es el «borrador para algo», mientras que el esbozo de nuestra vida es un esbozo para nada. En términos filosóficos diríamos que el hombre experimentado es precisamente el que no es dogmático. Dogma y experiencia son términos antagónicos. El que ha vivido realmente experiencias sabe que no hay experiencias últimas, ni definitivas, que siempre existe la posibilidad de otra experiencia, de una experiencia distinta, que contradiga la experiencia anterior (Gadamer, 1997, 432).

Una persona trata a otra con tacto cuando la considera única, es decir, cuando sabe que lo que es válido para uno no es válido para todo el mundo. A menudo los fracasos educativos vienen precisamente por el intento 
(supuestamente justo) de educar a todos por igual, de tratar a todos de la misma manera. «Tener tacto» es ser capaz de saber tratar a la otra persona como una singularidad incomparable, precisamente porque la misma palabra no significa para todo el mundo lo mismo. Es una obviedad, aunque muy a menudo los pedagogos parecen ignorarlo, el hecho de que cada palabra tiene significados distintos para cada persona, significados que dependen del tono, de la situación, de la atmósfera y de la sensibilidad de cada uno. «Tener tacto» (en alemán se usa la expresión Taktgefühl, «sentimiento de tacto») equivale a poseer el talento para oír, sentir y respetar la singularidad propia de las personas a las que se debe transmitir algo. «Tener tacto» significa saber salirse de uno mismo, tener una orientación hacia el otro, ser capaz de recibir al otro en su radical alteridad, ser sensible a sus demandas, a sus ruegos, a sus necesidades.

\section{Conclusión}

Necesitamos un lenguaje para la experiencia, para poder elaborar (con otros) el sentido o el sinsentido de nuestra experiencia, la tuya y la mía, la de cada uno, la de cualquiera. La experiencia es lo que nos pasa, no lo que pasa sino lo que nos pasa. Aunque tenga que ver con la acción, aunque a veces se dé en la acción, la experiencia no se hace sino se padece, no es intencional, no está del lado de la acción sino del lado de la pasión. Por eso la experiencia es atención, escucha, apertura, disponibilidad, sensibilidad, exposición. Si el lenguaje de la crítica elabora la reflexión del sujeto sobre sí mismo desde el punto de vista de la acción, el lenguaje de la experiencia elabora la reflexión de cada uno sobre sí mismo desde el punto de vista de la pasión. Lo que necesitamos, entonces, es un lenguaje en el que elaborar (con otros) el sentido 0 el sinsentido de lo que nos pasa y el sentido 0 el sinsentido de las respuestas que eso que nos pasa exige de nosotros. 
La experiencia lo es siempre de lo singular, no de lo individual o de lo particular sino de lo singular. Y lo singular es precisamente aquello de lo que no puede haber ciencia, pero sí pasión. La pasión lo es siempre de lo singular porque ella misma no es otra cosa que la afección por lo singular. En la experiencia, entonces, lo real se nos presenta en su singularidad. Por eso lo real se nos da en la experiencia como inidentificable (desborda cualquier identidad, cualquier identificación), como irrepresentable (se presenta de un modo que desborda cualquier representación), como incomprensible (al no aceptar la distinción entre lo sensible y lo inteligible desborda cualquier inteligibilidad) 0 , en otras palabras, como incomparable, irrepetible, extraordinario, único, insólito, sorprendente. Además, si la experiencia nos da lo real como singular, entonces la experiencia nos singulariza. En la experiencia nosotros somos también singulares, únicos, inidentificables e incomprensibles. La experiencia no puede ser anticipada, no tiene que ver con el tiempo lineal de la planificación, de la previsión, de la predicción, de la prescripción, ese tiempo en el que nada nos pasa, sino con el acontecimiento de lo que no se puede pre-ver, ni pre-decir, ni pre-scribir. Por eso la experiencia siempre lo es de lo que no se sabe, de lo que no se puede, de lo que no se quiere, de lo que no depende de nuestro saber, ni de nuestro poder, ni de nuestra voluntad. La experiencia tiene que ver con el no-saber, con el límite de lo que sabemos. En la experiencia siempre hay algo de «no sé lo que me pasa», por eso no puede resolverse en dogmatismo. La experiencia tiene que ver con el no-decir, con el límite del decir. En la experiencia siempre hay algo de «no sé qué decir», por eso no puede elaborarse en el lenguaje disponible, en el lenguaje recibido, en el lenguaje de lo que ya sabemos decir. La experiencia tiene que ver con el no-poder, con el límite del poder. En ella siempre hay algo de «no sé qué puedo hacer», por eso no puede resolverse en imperativos, en reglas para la práctica.

La experiencia exige otro lenguaje, un lenguaje atravesado de pasión, capaz de enunciar singularmente lo singular, de incorporar la incertidumbre. 
Con ese «necesitamos un lenguaje para la experiencia» quiero decirte que me gustaría poder hablar contigo, pensar contigo. Por eso me atrevo ahora a invitarte a abandonar los lenguajes dominantes de la pedagogía, tanto el lenguaje de la técnica, del saber y del poder, como el lenguaje de la crítica, de la voluntad y de la acción, esos lenguajes que no captan la vida, que están llenos de fórmulas, que se ajustan perfectamente a la lógica policial de la bio-política, lenguajes prestados de la economía, de la gestión, de las ciencias positivas que lo hacen todo calculable, identificable, medible, manipulable. Y, si te digo que «me gustaría poder hablar contigo», es también porque no sé en qué lengua, porque tendremos que buscar una lengua que esté entre nosotros, una lengua de la que lo único que sé es que no puede ser ni la tuya ni la mía, que nunca podrá ser la propia de ninguno de nosotros, pero en la cual, quizá, trataremos de hablarnos tú y yo, en nombre propio.

Ya basta de hablar (o de escribir) en nombre de la realidad, en nombre de la práctica, en nombre del futuro 0 en nombre de cualquier otra abstracción semejante. Ya basta de hablar (o de escribir) como expertos, especialistas, críticos, portavoces, ya basta de hablar (o de escribir) desde cualquier posición. Para poder hablarnos necesitamos hablar y escribir, leer y escuchar, tal vez pensar, en nombre propio, en primera persona, con las propias palabras, con las propias ideas. Obviamente, sólo podemos hablar (y escribir) con las palabras comunes, con esas palabras que son a la vez de todos y de nadie. Hablar (o escribir) con las propias palabras significa colocarse en la lengua desde dentro, sentir que las palabras que usamos tienen que ver con nosotros, que las podemos sentir como propias cuando las decimos, que son palabras que de alguna manera nos dicen aunque no sea de nosotros de quien hablan. Hablar (o escribir) en primera persona no significa hablar de uno mismo, ponerse a uno mismo como tema 0 contenido de lo que se dice, sino que significa, más bien, hablar (0 escribir) desde sí mismo, ponerse a sí mismo en juego en lo que uno dice o piensa, exponerse en lo que uno dice y en lo que uno piensa. Hablar (o escribir) 
en nombre propio significa abandonar la seguridad de cualquier posición enunciativa para exponerse en la inseguridad de las propias palabras, en 414 la incertidumbre de los propios pensamientos. Además, se trata de hablar (o de escribir), tal vez de pensar, en dirección a alguien. La lengua de la experiencia no sólo lleva la marca del hablante, sino también la del oyente, la del lector, la del destinatario siempre desconocido de nuestras palabras y de nuestros pensamientos. A diferencia de los que hablan (o escriben) para nadie 0 para extrañas abstracciones como el especialista, el estudiante, el experto, el profesional, o la opinión pública, hablar (o escribir) en nombre propio significa también hacerlo con alguien y para alguien. 
Agamben, G. (1998). El hombre sin contenido. Barcelona: Áltera.

Agamben, G. (2001). Infancia e historia. Buenos Aires: Adriana Hidalgo Editora.

Agamben, G. (2004). El estado de excepción. Homo sacer, 11.1. Valencia: Pre-Textos.

Arendt, H. (1997) ¿Qué es la política? Barcelona: Paidós.

Bárcena, F. (2004). El delirio de las palabras. Ensayo para una poética del comienzo. Barcelona: Herder.

Bauman, Z. (2005). Modernidad y ambivalencia. Barcelona: Anthropos.

Bauman, Z. y Tester, K. (2002). La ambivalencia de la modernidad y otras conversaciones. Barcelona: Paidós.

Blumenberg, H. (2004). Salidas de caverna. Madrid: Antonio Machado libros.

Derrida, J. (1995). Espectros de Marx. Madrid: Trotta.

Duch, L. (1997). La educación y la crisis de la modernidad, Barcelona: Paidós.

Foucault, M. (2000). Nietzsche, la genealogía, la historia. Valencia: Pre-Textos.

Gadamer, H.-G. (1997). Verdad y método. Salamanca: Sígueme.

Horkheimer, M. (2000). Anhelo de justicia. Madrid: Trotta.

Margalit, A. (1997). La sociedad decente. Barcelona: Paidós.

Nietzsche, F. (1979). Así habló Zaratustra. Madrid: Alianza.

Pardo, J. L. (2004). La regla del juego. Barcelona: Galaxia Gutenberg-Círculo de Lectores.

Paz, 0. (2003). Ideas y costumbres (La letra y el cetro. Usos y símbolos). Obras completas VI. Barcelona: Galaxia Gutenber g/Círculo de Lectores.

Quignard, P. (1988). Vie secrete. París: Gallimard.

Rombach, H. (2004). El hombre humanizado. Antropología estructural. Barcelona: Herder.

Serres, M. (1993). 0 tercero instruido. Lisboa: Instituto Piaget, 1993-

Valente, J. A. (2002). Las palabras de la tribu. Barcelona, Tusquets.

Van Manen, M. (1998). El tacto en la enseñanza. El significado de la sensibilidad pedagógica. Barcelona: Paidós.

Van Manen, M. (2004). El tono en la enseñanza. El lenguaje de la pedagogía. Barcelona: Paidós.

Éizek, S. (2002). ¿Quién dijo totalitarismo? Valencia: Pre-Textos. 